Working Paper 2010:7

Department of Economics

\title{
World Trade Patterns and Prices: The Role of Productivity and Quality Heterogeneity
}

Cristiana Benedetti Fasil and Teodora Borota 
Department of Economics

Uppsala University

P.O. Box 513

SE-751 20 Uppsala

Sweden

Fax: +46184711478
Working paper 2010:7

April 2010

ISSN $1653-6975$

World Trade Patterns and Prices: The Role

of Productivity and Quality Heterogeneity

Cristiana Benedetti Fasil and Teodora Borota

Papers in the Working Paper Series are published on internet in PDF formats.

Download from http://www.nek.uu.se or from S-WoPEC http://swopec.hhs.se/uunewp/ 


\title{
World Trade Patterns and Prices: The Role of Productivity and Quality Heterogeneity*
}

\author{
Cristiana Benedetti Fasil ${ }^{\dagger}$ and Teodora Borota ${ }^{\ddagger}$ \\ April 15, 2010
}

\begin{abstract}
This paper analyzes the role of product quality and labor efficiency in shaping the trade patterns and trade intensities within and across two groups of countries, the developed and richer North and the developing South. Taking prices as a proxy for quality, recent empirical literature identifies a positive relation between income per capita and both export and import prices, suggesting that rich countries trade goods of relatively higher quality. Instead of relying on specific demand side mechanisms such as non-homothetic preferences, we focus on the North-South differences in technology. We employ a four country North-South trade model with two dimensions of firm heterogeneity. Differences in firms' product qualities and cost efficiencies result in a price distribution generating different consumption bundles and the observed export and import prices across rich and poor countries. Furthermore, the resulting total expenditure allocation across quality shows that the North (South) spends a larger share of its income on high (low) quality even with the same homothetic preferences across regions.
\end{abstract}

JEL: F10, F12, F14, L11, L15

Keywords: International trade patterns, North-South trade, import and export prices, heterogeneous firms, product quality

*We would like to thank Omar Licandro and seminar participants at the European University Institute, Uppsala University, the 5th Danish International Economics Workshop, Stockholm University and the ASSET 2009 Meeting.

${ }^{\dagger}$ Contact: European University Institute, Via della Piazzuola 43, 50133 Firenze, Italy. email: cristiana.benedetti@eui.eu .

${ }^{\ddagger}$ Contact: Uppsala University, Department of Economics, P.O.Box 513, SE-751 20 Uppsala, Sweden. email: teodora.borota@nek.uu.se . 


\section{Introduction}

World trade patterns and their relation to the technological development and income per capita levels of the trading partners have been studied extensively in the theoretical and empirical literature. Employing either the traditional trade models or the new trade theory incorporating the notion of heterogeneous firms, the studies have focused on the determinants of the direction and intensity of trade flows and the empirical validity of such models. We wish to analyze import and export prices, and trade patterns within and across the regions of the North and the South (developed, relatively richer countries and developing countries, respectively). We provide a theoretical framework for this analysis in the form of a four country North-South trade model with heterogeneous firms in two dimensions, product quality and labor efficiency, and focus on intra-industry trade, particularly the manufacturing sector.

To the extent that the unit values of traded goods can represent quality, data on export and import prices might as well serve as evidence of countries' trade specialization and demand schedules over quality. Fieler (2007) finds that export prices increase with income per capita of the origin country. Schott (2004) presents evidence on positive variation of US import prices depending on the exporter's income per capita. Furthermore, it is found that import prices are positively related to income per capita, as well as that countries of different income per capita import goods of different prices from the same exporter. This evidence suggests that rich countries not only specialize in the production and export of relatively higher quality goods, but that they devote larger share of income on high quality imports and possibly high quality total consumption. ${ }^{1}$ Most of the literature that proposes a theoretical basis for this analysis starts from either non-homothetic preferences, where different income levels generate different demand structures, or standard preferences with arbitrarily imposed different "love for quality" parameters in the North and the South. The supply side mechanisms result in a comparative advantage in the production of goods that are in high domestic demand. Non-homothetic preferences might be the immediate natural assumption for explaining reported increase in traded goods' prices with income per capita, but are certainly not the only factor. Although the arbitrary parametrization of preferences might be regarded as a way around modeling the black box of demand heterogeneity across countries, non-homothetic preferences do have some empirical support in the micro-level data. The purpose of this paper is not to contradict these findings, but to show that when the

\footnotetext{
${ }^{1}$ These findings, however, should not be taken as a straightforward support for the differences in expenditure distribution over quality in the North and the South, as traded goods might present only a minor share of total consumption.
} 
attention is shifted from modeling preferences to modeling technology more closely, standard preferences model with fixed operational and trade cost can yield the stated predictions as well.

We wish to give more weight to the supply side mechanisms and their role in shaping the demand structure and therefore, we use homothetic preference structure. Specifically, the focus is on the technology endowments of the North and the South which are the main determinants of the production and export specialization, and the relative income per capita of the two regions. The North has a higher level of technological development, while the South lags behind the North and uses a lower level of technology. Firms in each region are heterogeneous in two technology (productivity) dimensions: product quality and labor efficiency which together determine the firms' domestic and foreign market profitability. Existing models of trade and heterogeneous firms that introduce only one productivity dimension, such as Melitz (2003), predict a negative relation between export prices and income per capita since higher technological development implies higher cost efficiency and thus lower prices. Empirical evidence on export prices calls for the introduction of the quality dimension of heterogeneity in a way that it generates positive relation between quality and price. In this sense, Northern technology allows this region to produce relatively higher quality-higher price varieties, while the South specializes in the production of lower quality-lower price varieties.

In this framework, the export decision of any firm depends on its quality-efficiency level which determines the profitability and thus the ability to cover the fixed cost of exporting. Consumers place greater value on products of higher quality, but quality also generates higher marginal cost of production. Baldwin and Harrigan (2007) develops a model of trade and heterogeneous firms in the quality dimension. They assume that quality rises faster than marginal cost and thus high quality-high cost varieties are the most profitable ones. Therefore, export profitability is increasing in quality (and price) monotonically. In that set-up, lower aggregate expenditure of the South implies that only the most profitable firms can cover the fixed cost of trade and export to the South, while the pool of exporters to the North is larger. However, this does not match the empirical evidence, as it results in the negative relationship between income per capita and import prices conditional on exporter. We introduce a separate measure of cost efficiency which affects the marginal cost independently of the quality. Each firm (variety) is characterized by a quality level which affects positively both utility and the cost of production, and by a labor efficiency level which decreases the marginal cost. Quality and efficiency together determine the productivity level of the firms, which are distributed across quality-efficiency pairs, with the Southern joint 
distribution having a lower mean due to its technological lag behind the North. With the two dimensions of heterogeneity, less profitable firms that export only to the North, also include those with highest quality but lower efficiency, and therefore a higher price. This contributes to a rise in the average import price with income per capita conditional on exporter. In this sense, Northern average import price is higher not because it consumes higher quality than the South, but due to the fact that it consumes also the high priced high quality varieties. Given the right-skewed distribution of firms in equilibrium, varieties of this type are relatively numerous and this amplifies the effect on the average import price and insures that North imports higher price varieties on average.

In aggregate terms, the greater income of the North compared to the South implies not only a greater expenditure on any good that is available in both regions, but higher levels in equal proportion across goods, due to homothetic preferences. However, with fixed cost of export only a subset of varieties is exported to foreign markets, and the resulting expenditure shares on certain quality are not equal across regions. The North spends a lower share of income on low quality varieties originated from the South, while the South spends a lower share on high quality produced in the North, both relative to the other region's share of expenditure on those varieties. If the income difference between the regions is sufficiently large, the statement above holds also in absolute terms. The South's larger share of income is allocated to domestic varieties of low quality, while the North spends more on the high quality produced domestically and imported from the other Northern country. Due to competition pressures from the South in the intermediate quality goods markets (lower quality portion of the production in the North), these varieties are only produced for the local market in the North, at a reduced scale. A part of these varieties are not exported by the South and thus not consumed by the North. More profitable varieties are exported by the South, but in a smaller share compared to those of a higher quality as they are in lower demand and are fewer.

The analysis of trade intensities within and across regions refers to the Linder hypothesis. Linder (1961) argues that on the demand side, countries with high (low) income per capita spend a larger fraction of their income on high (low) quality goods. On the supply side, countries develop a comparative advantage in the goods that are in high domestic demand, so high (low) income countries produce high (low) quality goods. Both these premises are predicted by our model, but Linder's hypothesis goes further. The demand and supply premises are combined in order to argue that the overlap of production and consumption patterns between countries of similar income per capita should induce them to trade more intensively with one another. Rich trade more with rich, while poor trade with poor. Our 
model predicts the highest intensity and value of the North-North trade. The ordering of the South-South and the North-South trade depends on the fixed and/or variable costs of trade, in particular on their asymmetries that are conditional on the origin and destination country. With symmetric costs, North-South trade is of higher value, but the result is reversed when stronger restrictions on Southern exports to the North are imposed. However, there is no robust empirical support of the Linder hypothesis. Namely, it is important to ascertain the level of aggregation at which the "Linder" mechanism might operate. Hallak (2008) shows that the trade intensities prediction is valid on both sides of income per capita distribution at the sectoral level (for some sectors), but is strongly rejected when data is aggregated over sectors.

The rest of the paper is organized as follows, Section 2 and Section 3 present the model and define the equlibrium, Section 4 discusses the results of the numerical exercise, while Section 5 concludes.

\section{The Model}

\subsection{Consumers}

We propose a two region North-South trade model where each region, the North and the South, consists of two symmetric countries (two symetric North and two symetric South). Consumers have equal, homothetic preferences across countries and regions. In every period, consumers choose consumption and supply labor inelastically at the wage rate $w^{N}$ in the North and $w^{S}$ in the South, with $w^{N}>w^{S}$. Labor is not mobile across regions and the aggregate measure of population in each country in the North and the South regions is $L^{N}$ and $L^{S}$, respectively. Consumers allocate optimally the aggregate consumption $X$ across differentiated varieties produced by domestic firms and those imported from abroad. The measure of available goods in each country is hence given by domestic goods of measure $I^{J D}$, imports from the other country of the same region, $I^{J J}$, and from the two countries of the other region, $I^{J K}$, with $J=\{N, S\}, J \neq K$. Thus, $I^{N}=I^{N D}+I^{N N}+2 I^{S N}$ for the North and similarly for the South, $I^{S}=I^{S D}+I^{S S}+2 I^{N S}$. We use the same index to represent both the region and the country of a particular region, as we assume symmetry in all environment dimensions of the countries within a region. However, the varieties they produce are perceived as different by the consumers and thus are all in demand, i.e. each country's consumers demand varieties from the other country of the same region as well as the goods of both countries of the other region. The utility function for country $J$ is given 
by a quality augmented Dixit-Stiglitz utility function,

$$
U^{J}(t)=\left(\int_{i \in I^{J}}(q(i) x(i, t))^{\alpha} d i\right)^{\frac{1}{\alpha}}
$$

where $x(i, t)$ is the quantity and $q(i)$ is the quality of a variety $i \in I^{J}$ consumed at time $t$. The standard CES utility index is augmented to account for the quality variation across products where quality acts as a utility shifter: a consumer prefers high quality over low quality products. The elasticity of substitution between any two goods is constant and equal to $\sigma=1 /(1-\alpha)>1$, with $\alpha \in(0,1)$.

Consumers derive the optimal demand for each good, both domestic and foreign, maximizing their utility subject to the individual budget constraint $E^{J}(t)=\int_{i \in I^{J}} p(i, t) x(i, t) d i$, where $E^{J}(t)$ presents total expenditure in country $J$ and $p(i, t)$ is the price of variety $i \in I^{J}$ at time $t$. The demand for product $x(i, t)$ is given by

$$
x(i, t)=\left(\frac{P^{J}(t) q^{\alpha}(i)}{p(i, t)}\right)^{\frac{1}{1-\alpha}} X^{J}(t)=\left(\frac{q^{\alpha}(i)}{p(i, t)}\right)^{\frac{1}{1-\alpha}} P^{J}(t)^{\frac{\alpha}{1-\alpha}} E^{J}(t)
$$

with $P^{J}(t)$ as the price-quality index defined by

$$
P^{J}(t)=\left(\int_{i \in I^{J}}\left(\frac{p(i, t)}{q(i, t)}\right)^{\frac{\alpha}{\alpha-1}} \mathrm{~d} i\right)^{\frac{\alpha-1}{\alpha}} \text { and } X_{t}=U_{t} .
$$

Although consumer preferences are the same in both regions, the bundles of varieties consumed are different. Due to fixed cost of export, a subset of varieties in each region is not exported, resulting in a different consumption composition and price schedules across regions. This yields different price indices as averages of the quality weighted prices of all varieties consumed by a region, domestically produced and imported.

This paper focuses on the analysis of the steady-state equlibrium in which all variables are constant and we omit the time subscrips in the further text.

\section{$2.2 \quad$ Firms}

Firms in each region differ in two dimensions of firm heterogeneity. The first source of heterogeneity is labor efficiency(in further text, efficiency), $a(i) \in \mathbb{R}_{++}$, which increases the marginal productivity of labor, as in the seminal paper of Hopenhayn (1992). The second source is quality of a firm's variety, $q(i) \in \mathbb{R}_{++} \backslash(0,1)$, which decreases the marginal productivity of labor. In this respect, a higher quality variety implies a higher variable cost 
as in Verhoogen (2008), but contributes positively to consumers' utility. The production technology has the following form

$$
x(i)=\frac{a(i)^{\chi}}{q(i)^{\eta}} n(i)
$$

where $n(i)$ is the production labor employed by firm $i$ and $\chi, \eta \in(0,1)$. Firms in both regions distribute over quality and efficiency, and we assume that each firm produces only one variety so that the index $i$ identifies both the firm and the corresponding variety it produces. Firms in the North lead in both productivity dimensions while firms in the South lag behind the more advanced Northern technology.

In both regions firms enter and exit the market and the industry is characterized at the steady-state equilibrium.

\subsubsection{Production decision}

Each firm is the monopolistic producer of its own variety. Firms pay a fixed operational cost, $c_{f}$, expressed in terms of labor in order to produce, and incur an iceberg export cost $\tau>1$ in the units of output and a fixed export $\operatorname{cost} c_{e x}$, expressed in terms of labor, in order to export. ${ }^{2}$ The fixed operational cost is necessary to trigger exit while the fixed export cost generates the partition between exporter and non exporter firms. Given the same labor requirement for the fixed cost of operation and export in the North and the South, it follows that both costs are higher in the North due to its higher wage.

Solving the standard monopolistic problem, firms in each country $J$ charge a price $p^{J D}$ in the domestic market and a price $p^{J X}$ in the foreign market which takes into account the iceberg cost. That is

$$
p^{J D}=\frac{w^{J} q^{\eta}}{\alpha a^{\chi}}
$$

for the products sold in the domestic market and

$$
p^{J X}=\frac{\tau w^{J} q^{\eta}}{\alpha a^{\chi}}
$$

for the products sold in the foreign markets. Substituting these expressions for prices in the demand function it follows that $x(i)$ is increasing in $a$ and it is decreasing in $q$ iff $\eta>\alpha$. We restrict our attention to the specification when this condition holds.

\footnotetext{
${ }^{2}$ In the benchmark model we assume symmetric $\tau$ across regions in order to abstract from this form of relative price distortion across regions and analyze only the effect of the fixed cost of export on the patterns of trade.
} 
Firms total profits are the sum of the profits obtained in the domestic market and the profits from the foreign markets when it is profitable to export. Hence the optimal profits with $J, K=\{N, S\}, J \neq K$ are given by

$$
\begin{aligned}
\pi^{J}(a, q) & =\pi^{J D}(a, q)+\max \left\{0, \pi^{J J}(a, q)\right\}+2 \max \left\{0, \pi^{J K}(a, q)\right\} \\
\pi^{J D}(a, q) & =\left(\frac{a^{\chi} q^{1-\eta} \alpha}{w^{J}}\right)^{\frac{\alpha}{1-\alpha}}(1-\alpha) P^{J \frac{\alpha}{1-\alpha}} E^{J}-w^{J} c_{f} \\
\pi^{J J}(a, q) & =\tau^{\frac{\alpha}{\alpha-1}}\left(\frac{a^{\chi} q^{1-\eta} \alpha}{w^{J}}\right)^{\frac{\alpha}{1-\alpha}}(1-\alpha) P^{J \frac{\alpha}{1-\alpha}} E^{J}-w^{J} c_{e x} \\
\pi^{J K}(a, q) & =\tau^{\frac{\alpha}{\alpha-1}}\left(\frac{a^{\chi} q^{1-\eta} \alpha}{w^{J}}\right)^{\frac{\alpha}{1-\alpha}}(1-\alpha) P^{K \frac{\alpha}{1-\alpha}} E^{K}-w^{J} c_{e x}
\end{aligned}
$$

Since export profits depend on the aggregate variables of the foreign region, this is the channel through which the aggregate economy of the foreign region affects the profitability of the domestic firms.

The max operator in $\pi^{N}$ and $\pi^{S}$ indicates the choice of each firm to specialize only in the domestic market, or to open to foreign markets when the profits derived from exporting exceed the fixed cost of export, $c_{e x}$. This choice depends on both efficiency and quality of the variety produced by the firms. The specification of $\chi$ and $\eta$ affects not only the concavity of profits in the two productivity dimensions, but also the ratio of the profit elasticities with respect to each dimension. With $\chi$ bigger (smaller) than $1-\eta$ the profits increase faster along the efficiency (quality) dimension, which shapes the isoprofit curves in the $(a, q)$ space and thus the export productivity treshold functions.

The two sources of firm heterogeneity imply that the thresholds that characterize the border between export and not export are given by the infinite combinations of the (a,q) couples. For this reason, it becomes convenient to express the reservation values in terms of efficiency as a function of quality ${ }^{3}, a(q)$, and to obtain a cutoff function rather than cutoff values as in one factor heterogeneous firm models. For a given $q \in Q$ it is possible to define the following export cutoff functions for the North and the South, with $J, K=\{N, S\}, J \neq K$,

\footnotetext{
${ }^{3}$ It is equivalent to express product quality as a function of efficiency, $q(a)$. Using a specific formulation for the cut-off function does not affect the implications of the model.
} 


$$
\begin{gathered}
a_{e x}^{J J}(q)=\left[\left(\frac{w^{J} c_{e x}}{(1-\alpha) P^{J \frac{\alpha}{1-\alpha}} E^{J}}\right)^{\frac{1-\alpha}{\alpha}} \frac{1}{\alpha} \frac{w^{J} \tau}{q^{1-\eta}}\right]^{\frac{1}{\chi}} \\
a_{e x}^{J K}(q)=\left[\left(\frac{w^{J} c_{e x}}{(1-\alpha) P^{K \frac{\alpha}{1-\alpha}} E^{K}}\right)^{\frac{1-\alpha}{\alpha}} \frac{1}{\alpha} \frac{w^{J} \tau}{q^{1-\eta}}\right]^{\frac{1}{\chi}}
\end{gathered}
$$

The cutoff functions are decreasing in quality which implies that a firm characterized by a low level of efficiency but a high quality may still find it optimal to export. However, with $\chi>1-\eta$, the cutoff efficiency is decreasing in quality at a decreasing rate. We assume this condition holds, as it captures the idea of increasing difficutly in keeping the export market shares for the firms that produce high quality varieties with low efficiency which results in a high price. In other words, this assumption represents minimum (cost) efficiency requirements for exporting.

Given that the export decision depends on the aggregate variables of the foreign country, the export cutoff functions depend on the foreign aggregates as well. The cutoff functions are increasing in the wage of the exporting country as higher wage implies higher fixed cost of export and higher export price, while they decrease in the total expenditure and the price index of the destination country. Higher expenditure (income) of the destination market implies higher purchasing power of the market, while higher price index represents lower competition pressures on the exporting firm. As the total expenditure depends on the size of the population in the destination country, it follows that a larger export market implies higher profitability and lower cutoff productivity levels. The order of the cutoffs for export to different regions is determined by the ratio of the aggregates of the two regions, $P^{\frac{\alpha}{1-\alpha}} E$. The condition that results in larger export cutoff compared to the operation cutoff productivity level in both regions, and the discussion on the effect of the aggregates is presented in Appendix A.

\subsubsection{The exit decision}

Every firm faces an exogenous probability of a bad shock $\delta$ which forces the firm to exit the market. Besides this exogenous exit, firms exit the market when their profits are not enough to cover the fixed operational cost, $c_{f}$. The exit cutoff functions for given $q \in Q$ for both North and South, $J=\{N, S\}$, are given by

$$
a_{x}^{J}(q)=\left[\left(\frac{w^{J} c_{f}}{(1-\alpha) P^{J \frac{\alpha}{1-\alpha}} E^{J}}\right)^{\frac{1-\alpha}{\alpha}} \frac{1}{\alpha} \frac{w^{J}}{q^{1-\eta}}\right]^{\frac{1}{\chi}} .
$$


The exit cutoff functions are decreasing in quality produced: high quality allows for an easier survival. However, the exit cutoffs depend only on the domestic aggregates. In other words, for a given quality firm partition in both the North and the South is such that firms with low level of efficiency $(a)$ exit the industry, firms with intermediate levels produce only for the domestic market, while the most efficient firms produce for both the domestic and the foreign markets, first for the market in the North and then for the foreign markets in both regions. The stated order of the firm partition is assured by the conditions on the fixed costs of operation and export. ${ }^{4}$ The rest of the model is then derived assuming that these conditions hold, and hence only some of the firms in both the North and the South survive and only some of the successful firms export.

\subsubsection{Firms entry}

Each period, $M^{J}$ firms enter the industry and pay a sunk entry cost, $c_{e}$, expressed in terms of labor. After paying the entry cost they draw the product quality and efficiency level (productivity vector $(\mathrm{a}, \mathrm{q}))$ from a bivariate distribution $G^{J}(a, q), J=\{N, S\}$, with corresponding density $g^{J}(a, q)$. The density function in the North, $g^{N}(a, q)$, is assumed to be log-normal and exogenous while $g^{S}\left(a, q \mid \bar{\mu}^{N}\right)$ is log-normal but its mean, $\bar{g}^{S}$, is determined as a fraction of the incumbents joint mean in the North, $\bar{\mu}^{N}$, which will be defined in the next section. ${ }^{5}$ The assumption attempts to capture the idea of imitative R\&D in the South which copies the technology of the North at a certain lag due to high difficulty of copying the advanced goods. As we don't model the R\&D process endogenously, we might justify this assumption by the evidence on differences in North-South TFP levels documented in the literature. ${ }^{6}$

We assume that the free entry condition holds in equilibrium. Firms in the North and the South enter the industry until the expected value of the firm, $\bar{v}$, is equal to the entry costs. With the value of the firm given as the discounted future flow of profits, and with no time discounting as in Melitz (2003), the free entry condition reads

$$
\bar{v}^{J}=\int_{a_{x}^{J}(q)} \int_{Q} \frac{\pi^{J}(a, q)}{\delta} g^{J}(a, q) \mathrm{d} q \mathrm{~d} a=w^{J} c_{e},
$$

\footnotetext{
${ }^{4}$ See Appendix A. for the discussion on exit and export cutoffs.

${ }^{5}$ This specification is similar to the one used in Gabler and Licandro (2005).

${ }^{6}$ See for example, Cordoba and Ripoll (2008), Jerzmanowski (2007), Hall and Jones (1999).
} 


\subsection{Cross sectional distribution and aggregates}

The density of firms conditional on successful entry is computed as

$$
\mu^{N}(a, q)= \begin{cases}\frac{g^{N}(a, q)}{P_{i n}^{N}} & \text { if } a \geq a_{x}^{N}(q) \\ 0 & \text { otherwise }\end{cases}
$$

for the North firms and similarly for the South firms,

$$
\mu^{S}(a, q)= \begin{cases}\frac{g^{S}(a, q)}{P_{i n}^{S}} & \text { if } a \geq a_{x}^{S}(q) \\ 0 & \text { otherwise }\end{cases}
$$

where $P_{i n}^{N}=\int_{a_{x}^{N}(q)} \int_{Q} g^{N}(a, q) \mathrm{d} q \mathrm{~d} a$ and $P_{i n}^{S}=\int_{a_{x}^{S}(q)} \int_{Q} g^{S}\left(a, q \mid \bar{\mu}^{N}\right) \mathrm{d} q \mathrm{~d} a$ are the ex-ante probabilities of surviving for the firms in the North and the South, respectively. In a similar way we can define the ex-ante probability that a successful firm exports. That is, $P_{e x}^{N N}=\frac{1-G\left(a_{e x}^{N N}(q), q\right)}{P_{i n}^{N}}, P_{e x}^{N S}=\frac{1-G\left(a_{e x}^{N S}(q), q\right)}{P_{i n}^{N}}, P_{e x}^{S N}=\frac{1-G\left(a_{e x}^{S N}(q), q\right)}{P_{i n}^{S}}$ and $P_{e x}^{S S}=\frac{1-G\left(a_{e x}^{S S}(q), q\right)}{P_{i n}^{S}}$ for North and South.

To compute the weighted mean of Northern productivity, necessary to determine the distribution of the firms in the South, we need to define the mass of incumbents in each country. Hence, $I^{N D}$ and $I^{S D}$ also represent the measure of varieties produced in each country of the North and the South, so $I_{e x}^{N N}=P_{e x}^{N N} I^{N D}, I_{e x}^{N S}=P_{e x}^{N S} I^{N D}, I_{e x}^{S N}=P_{e x}^{S N} I^{S D}$ and $I_{e x}^{S S}=P_{e x}^{S S} I^{S D}$ are the masses of exporting firms and exported varieties in the North and the South, respectively. This means that the mass of available varieties in each country is given by the mass of varieties produced domestically plus the mass of varieties imported: $I^{N}=I^{N D}+I_{e x}^{N N}+2 I_{e x}^{S N}$ for the North, and $I^{S}=I^{S D}+I_{e x}^{S S}+2 I_{e x}^{N S}$ for the South.

The average weighted productivity for the North is computed taking into account not only the output share of the domestic firms, but the additional export share of the better firms and the proportion $\tau$ of output lost during the export transit:

$$
\begin{aligned}
\bar{\mu}^{J} & =\left(\frac{I^{J D}}{\left(I^{J D}+I_{e x}^{J J}+2 I_{e x}^{J K}\right)} \bar{\mu}_{x}^{J D \frac{\alpha}{1-\alpha}}+\frac{I_{e x}^{J J}}{\left(I^{J D}+I_{e x}^{J J}+2 I_{e x}^{J K}\right)}\left(\frac{\bar{\mu}_{e x}^{J J}}{\tau}\right)^{\frac{\alpha}{1-\alpha}}\right. \\
& \left.+\frac{2 I_{e x}^{J K}}{\left(I^{J D}+I_{e x}^{J J}+2 I_{e x}^{J K}\right)}\left(\frac{\bar{\mu}_{e x}^{J K}}{\tau}\right)^{\frac{\alpha}{1-\alpha}}\right)^{\frac{1-\alpha}{\alpha}}
\end{aligned}
$$


where $J, K=\{N, S\}, \mathrm{J} \neq \mathrm{K}$ and

$$
\begin{aligned}
\bar{\mu}_{x}^{J D} & =\left(\int_{a_{x}^{J}(q)} \int_{Q}\left(a^{\chi} q^{1-\eta}\right)^{\frac{\alpha}{1-\alpha}} \mu^{J}(a, q) \mathrm{d} q \mathrm{~d} a\right)^{\frac{1-\alpha}{\alpha}} \\
\bar{\mu}_{e x}^{J J} & =\left(\int_{a_{e x}^{J J}(q)} \int_{Q}\left(a^{\chi} q^{1-\eta}\right)^{\frac{\alpha}{1-\alpha}} \tilde{\mu}_{e x}^{J J}(a, q) \mathrm{d} q \mathrm{~d} a\right)^{\frac{1-\alpha}{\alpha}} \\
\bar{\mu}_{e x}^{J K} & =\left(\int_{a_{e x}^{J K}(q)} \int_{Q}\left(a^{\chi} q^{1-\eta}\right)^{\frac{\alpha}{1-\alpha}} \tilde{\mu}_{e x}^{J K}(a, q) \mathrm{d} q \mathrm{~d} a\right)^{\frac{1-\alpha}{\alpha}} .
\end{aligned}
$$

Variables $\tilde{\mu}_{e x}^{J J}(a, q)$ and $\tilde{\mu}_{e x}^{J K}(a, q)$ are the conditional distributions of firms exporting to the North and of firms exporting to both regions, respectively, given that the firm survives in the market.

\subsection{Steady-state equilibrium}

The steady state equlibrium is characterized by prices $\left(p^{J D}, p^{J X}\right)$, wages $\left(w^{J}\right)$, exit and export cutoff functions $\left(a_{x}^{J}(q), a_{e x}^{J J}(q), a_{e x}^{J K}(q)\right)$, firm distributions $\left(\mu^{J}\right)$, number of firms in each region $\left(I^{J D}\right)$ and the aggregate expenditure and price indices $\left(E^{J}, P^{J}\right)$ such that

- consumers choose consumption optimally and firms choose prices to maximize their profits

- exit and export cutoff functions satisfy the conditions given in section 2.2.1 and 2.2.2

- entry and exit are such that the condition $\delta I^{J D}=P_{i n}^{J} M^{J}$ and the free entry condition are satisfied

- distribution of firms in the North and the South are given by equations in section 2.3

- number of operating firms is such that the labor markets clear, i.e. total labor is used for domestic and export production and also for the fixed cost of entry, operation and export

$$
\begin{aligned}
& L^{J}=\int_{a_{x}^{J}(q)} \int_{Q} n(a, q) \mu^{J}(a, q) I^{J D} \mathrm{~d} q \mathrm{~d} a+\int_{a_{e x}^{J J}(q)} \int_{Q} n(a, q) \mu^{J}(a, q) I^{J D} \mathrm{~d} q \mathrm{~d} a \\
& +\int_{a_{e x}^{J K}(q)} \int_{Q} n(a, q) \mu^{J}(a, q) I^{J D} \mathrm{~d} q \mathrm{~d} a+c_{e} M^{J}+c_{e x}\left(P_{e x}^{J J}+P_{e x}^{J K}\right) I^{J D}+c_{f} I^{J D}
\end{aligned}
$$


- the trade balance condition is satisfied, implying that the bilateral North-North, SouthSouth, North-South and South-North trade is balanced. ${ }^{7}$

We solve the model numerically using the value of parameters which are calibrated to match the recent data on the aggregate trade values (shares of North-North, North-South and South-South exports in the total world exports, relative wage of the South compared to the North) and the firm-level variables.

\subsection{Calibration}

In our quantitative exercise we choose the preference parameter, $\alpha$, exponents on productivity and quality in the production function, $\chi$ and $\eta$, exogenous exit probability, $\delta$, the variable trade cost, $\tau$, the size of the countries, $L^{N}$ and $L^{S}$, and the mean of the entrants in the North, $\bar{g}^{N}$. $\alpha$ is set equal to 0.73 to match a mark-up over the marginal cost of $36 \%{ }^{8} \chi$ and $\eta$ are equal to 0.5 and 0.86 , respectively. The results do not change qualitatively if $\chi$ and $\eta$ change as long as the conditions on these two exponent are satisfied. The exogenous death probability is fixed equal to $0.5 \%$ and hence firms's life expectancy is a priori of 200 years. ${ }^{9}$ We assume that $\tau$ is symmetric across the four countries and equal to one to avoid exogenous price distortions. Finally, $L^{N}, L^{S}$, and $\bar{g}^{N}$ scale and locate the economy in the space $(a, q)$. The population is assumed to be the same in both the North and the South and normlized to one while $\bar{g}^{N}$ is set equal to 4 .

The remaining parameters are the technological gap between the North and the South, $\theta$, the fixed cost of entry, $c_{e}$, the fixed operational cost, $c_{f}$, the fixed cost of export, $c_{e x}$, and the entrants distribution variance for the North and the South (assuming equal variance over productivity and quality and across countries). These parameters are calibrated to match a number of salient feature related to the 2006 data on the within and across region export shares in the total world exports, exit and entry rates in the manufacturing industry and the South-North relative wage. The data on export shares are taken from The OECD Policy Brief "South-South Trade:Vital for Development", August 2006, available at: www.oecd.org/publications/Policybriefs and Goksel 2008. The reported export shares are

\footnotetext{
${ }^{7}$ Due to symmetry between the countries of the same region, trade balance depends only on the values of export flows between countries of different regions in equlibrium.

${ }^{8}$ For more details on mark-ups in models with heterogenous firms and fixed costs see Ghironi and Melitz 2005.

${ }^{9}$ Atkeson and Burstein 2007 and Luttmer 2007 find the same value calibrating $\delta$.
} 
$52.69 \%$ for the North-North trade, $40.86 \%$ for the North-South and $6.45 \%$ for the SouthSouth exports. Bartelsman et al. (2004) compute that the average firms exit rate in the data for the North is around 10\%, while it is slightly higher in the South, 20\%. Accordingly to the World Bank, International Comparison Program database, online edition, 2009 the relative South-North wage in the manufacturing sector is on average 0.4 .

Table 2 in Appendix B summarizes the parameters values both exogenously set and calibrated, the empirical targets used for the calibration and the corresponding model moments.

\section{Results}

This section presents the numerical results of the North-South trade model with four countries, two symmetric Norths and two symmetric Souths. Given the productivity lag of the entrants in the South behind the incumbents in the North, the selection of the firms in the equilibrium results in the distribution of operating firms over productivity vectors in the North and the South as presented in Figure 1. The equilibrium productivity lag of the South results in the positive North-South wage differential in equilibrium.

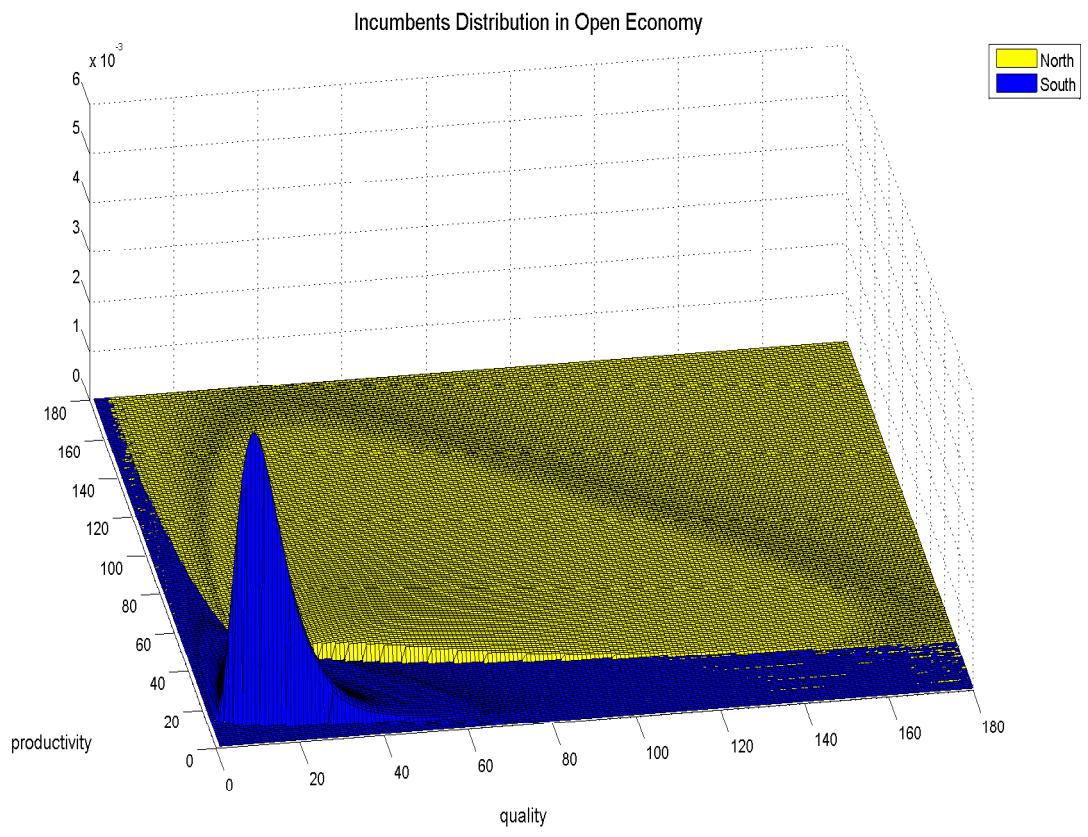

Figure 1: Incumbents distribution over productivity and quality

When the North and the South are open to trade, the South produces the low produc- 
tivity varieties that are demanded domestically but also by the North whose international competitiveness in this portion of the distribution is weakened due to lower production cost in the South. On the other hand, Northern firms are more spread out on the whole remaining area of the productivity space, higher efficiency and higher quality. Few firms in the South reach these productivity levels and thus the North specializes in the production and export of higher $(a, q)$ varieties.

Figure 2. presents the partitioning of the firms across the $(a, q)$ space into exiting firms, domestic producers and exporters of two types, those that export only to the North and those that export both to the North and the South. Analyzing the partition over the efficiency dimension, the lowest $a$ firms exit the industry in both regions, but the exit cutoff in the North is higher than in the South due to higher absolute value of the fixed operational cost. Therefore, it can be observed that the low efficiency varieties are consumed exclusively by the South as the North exits this market, and as the South does not export due to low profitability. The North-South head-on competition occurs in the intermediate efficiency range of varieties. Southern varieties are more competitive and are exported to the North, while the North produces them only for the domestic consumption at a reduced scale. At even higher levels of efficiency, the number of Southern firms (varieties) decreases. This is principally the market for Northern exporters who employ a large share of the total labor force in the North. Details on labor (size) distribution of firms and the values of average productivities across different areas of the $(a, q)$ space in the North and the South are presented in Appendix C.

Bearing in mind the price schedule over the $(a, q)$ space, the partitioning graph provides a graphical explanation for positive relationship between the average export and import prices on one side and income per capita on the other. With $\chi>1-\eta$ the profits increase faster along the efficiency dimension, which shapes the isoprofit curves (cutoff functions) in the $(a, q)$ space as presented in Figure 3.

The shape of the cutoff functions determines the quality and price composition of the domestic and import bundles of the two regions. The most profitable firms export both to the North and the South, while less profitable export only to the North. With $\chi>1-\eta$, the bigger share of the relatively higher priced varieties (high $q$ and low $a$ ) are not exported from the North to the South and are shipped only to the North. ${ }^{10}$ Thus, the resulting average import price is higher for the North. Moreover, given the exporting country, Northern imports are of higher average quality relative to the imports of the South as more high

\footnotetext{
${ }^{10}$ As opposed to the case with $\chi<1-\eta$ when relatively low priced varieties are excluded from exports to the South in a larger share than the high priced varieties.
} 

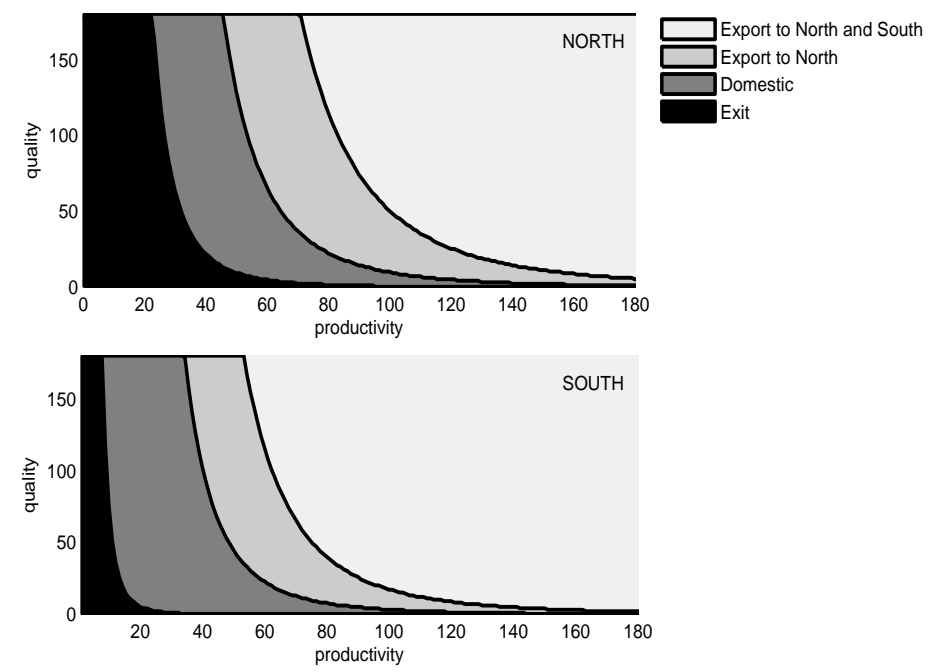

Figure 2: Firms partition

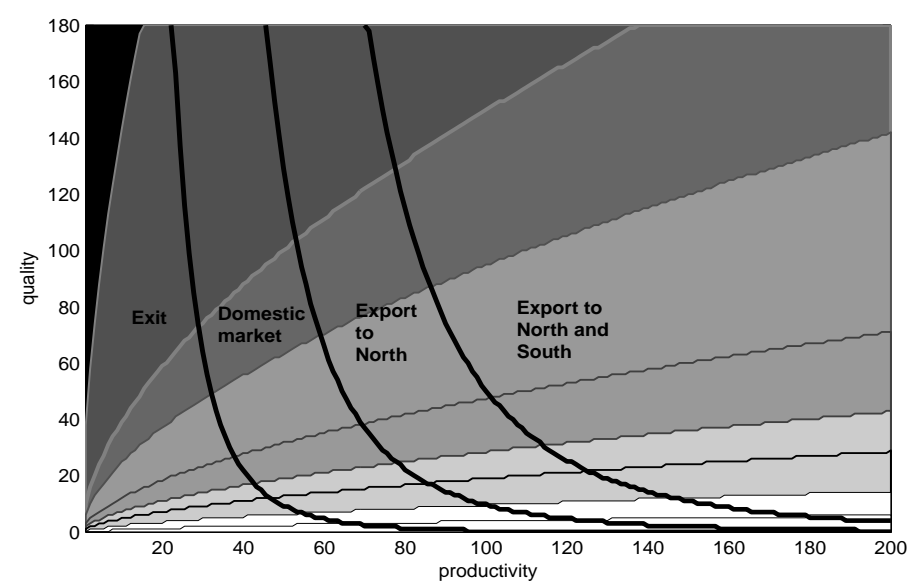

Figure 3: Distribution of prices

quality varieties are included in its import bundle. This effect is not present with only one dimension of firms heterogeneity as the profits are just a monotonic transformation of the price and the unique productivity measure. The North abandons the export of low price varieties due to competition from the South, which results in higher export prices of the North. However, it imports goods of higher average price not as it consumes higher quality than the South but due to the fact that it additionally consumes the high priced high quality varieties. The analogue reasoning applies to the imports from the South. Average prices of 
export and import are presented in Table 1.

\begin{tabular}{l|c|c}
\hline \hline Average Price & North & South \\
\hline Exports & 4.0739 & 0.9495 \\
Imports & 1.0072 & 0.9101 \\
\hline Imports from North & 4.2514 & 3.9861 \\
Imports from South & 1.0008 & 0.9054 \\
\hline \hline
\end{tabular}

Table 1: Average Import Prices

The following graph (Figure 4.) presents the expenditure shares distribution of the two regions across different levels of quality for a given efficiency of the firm. Northern demand is relatively higher for the varieties produced by the high quality firms, and the South is demanding relatively more of the goods in the lower quality portion of the distribution, which is the effect of the fixed cost of trade. With no fixed cost, the homothetic preferences would result in a lower demand from the South but still in levels exactly proportional to those of the North. Once the fixed cost of export is introduced in both the North and the South, this results in subsets of firms with only domestic sales, which subsequently distorts the proportionality of the consumption shares of the two regions across varieties.

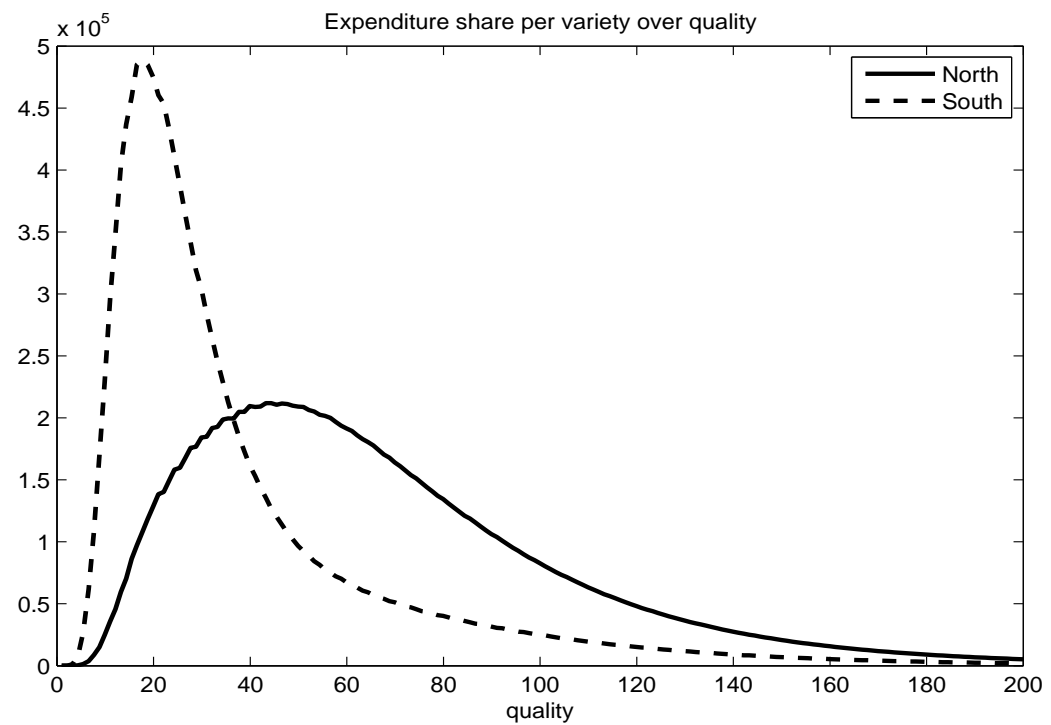

Figure 4: Expenditure shares distribution over quality 
Figure 5. shows the total trade values within and across two groups of countries with no asymmetries in the variable costs of trade. The model implies that larger shares of Northern export revenue is coming from the North due to higher profitability requirements for the export to the South and low absolute expenditure of the South. This implies higher import between countries of the North. As a result, the North-North trade is the largest compared to the other trade flows, North-South and South-South. In this set-up North-South trade is of higher value than the South-South trade, but the ranking reverses when the asymmetric variable costs of trade are introduced, with the highest cost imposed on Southern exports to the North. Some empirical evidence points to these asymmetries in the form of higher export barriers imposed on the exporters from the South (such as iceberg trade cost, quality requirements, tariffs). In sectors with these asymmetries, our model's results might support the final conjecture of the Linder hypothesis, besides predicting the demand and supply premises.

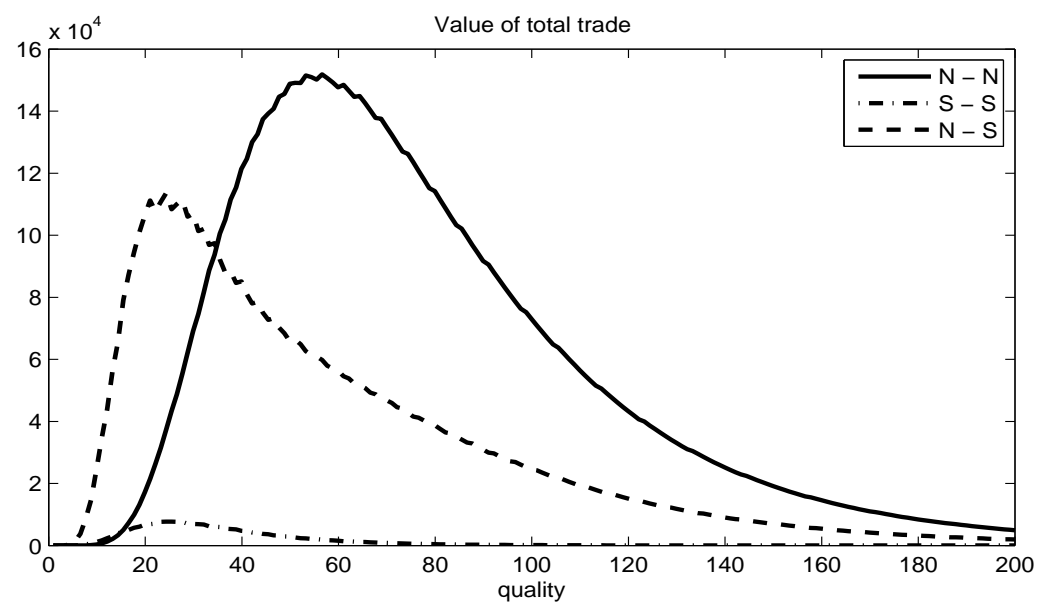

Figure 5: Total trade values within and across regions

\section{Conclusion}

This paper analyzes the role of efficiency and quality in shaping the trade patterns and trade intensities within and across two groups of countries, the developed and richer North and the developing South. We employ a four country North-South trade model with two dimensions 
of firm heterogeneity. Matching the empirical values of within and across region export shares in the total world exports, we show that the equlibrium results support the ranking of the average prices of tradables within and across regions as found in the data. This result is not previously found in the literature since using only one technology dimension does not simultaneously allow for increasing relation between export prices, import prices and import prices conditional on exporter on one side and income per capita on the other.

Furthermore, we find differences in the consumption bundles across regions even though the preferences are of standard, homothetic form. Namely, the resulting total expenditure allocation across quality shows that the North spends a larger share of its income on high quality while the South allocates more of its expenditure on low quality varieties. Therefore, we wish to stress that the trade patterns in this model are not determined by the nonhomotheticity of preferences and therefore do not originate exclusively from the demand structures. The results mainly come from the supply side through the productivity distribution of incumbents and its effect on prices. This in turn allows the fixed cost of exporting to act in a way that the empirically observed trading pattern is replicated. In other words, it is not that the consumers alone have different preferences over qualities based on their income but differences in productivity and income (coming endogenously from the productivity level) are the principal deciding factors.

The future research agenda calls for the development of an endogenous R\&D mechanism which will determine technology level of the North and the South in equilibrium. In this hypothetical set-up, firm would choose the level of their investment in technology, which would affect the initial productivity draw through the innovation in the North and technology adoption in the South. R\&D incentives would come partly from the domestic demand structure but also as a response to foreign demand, which would together shape the comparative advantage of each region over quality segments. This allows for the analysis of several issues such as trade liberalization, income inequality and $R \& D$ subsidies to promote welfare. Furthermore, it should be noted that the set-up is easily extendable to include $n$ countries which allows for more empirically testable predictions.

\section{References}

Aghion, P. and Howitt, P., (1992). A Model of Growth through Creative Destruction, Econometrica, 60, 323-351. 
Baldwin, R. and Harrigan, J., (2007). Zeros, Quality and Space: Trade Theory and Trade Evidence, CEPR Discussion Paper No. 6368.

Bartelsman, E., Haltiwanger J. and Scarpetta S., (2004). Microeconomic Evidence of Creative Destruction in Industrial and Developing Countries Eric Bartelsman, Tinbergen Institute Discussion Paper, 04-114/3.

Bernard, A.B., Redding, S.J. and Schott, P.K., (2009). Products and Productivity, mimeo

Brooks, E.L., (2006). Why don't firms export more? Product quality and Colombian plants, Journal of Development Economics, 80, 160- 178.

Choi, Y.C., Hummels, D. and Xiang, C., (2006). Explaining Import Variety and Quality: The Role of the Income Distribution, NBER Working Paper 12531.

Coibion, O., Einav, L. and Hallak, H.C., (2007). Equilibrium demand elasticities across quality segments, International Journal of Industrial Organization, 25, 13-30.

Cordoba, J.C. and Ripoll, M., (2008). Endogenous TFP and cross-country income differences, Journal of Monetary Economics, 55, 11581170.

Ghironi, F. and Melitz. M.J., (2005). International Trade and Macroeconomics Dynamics with Heterogenous Firms, Quarterly Journal of Economics, 120(3), 865-915.

Fieler, C., (2007). Non-Homotheticity and Bilateral Trade: Evidence and a Quantitative Explanation, New York University, mimeo.

Fieler, C., (2007). Quality Differentiation in International Trade: Evidence from the Demand and Supply Sides, New York University, mimeo.

Flam, H. and Helpman, E., (1987). Vertical Product Differentiation and North-South Trade, The American Economic Review, 77(5), 810-822.

Fontagné, L. and Freudenberg, M., (2002). "Long-term Trends in IIT", Chapter 8 of Frontiers of Research on Intra-industry Trade, Peter Lloyd Hyun Lee eds, Palgrave, 131158.

Fontagne, L., Guillaume, G. and Zignago, S., (2008). Specialization across varieties and North-South competition, Economic Policy, 23 (53), 51-91.

Gabler, A. and Licandro, O., (2005). Endogenous Growth through Selection and Imitation, European University Institute, mimeo.

Goksel, T., (2008). Income, Trade Barriers, and International Trade, University of Minnesota, mimeo.

Grossman, G. M. and Helpman, E., (1991). Innovation and Growth in the Global Economy, MIT Press, Cambridge MA.

Hall, R.E. and Jones, C.I., (1999). Why Do Some Countries Produce So Much More 
Output Per Worker Than Others?, The Quarterly Journal of Economics, MIT Press, 114(1), 83-116.

Hallak, J.C., (2006). A Product-Quality View of the Linder Hypothesis, NBER Working Paper No.12712.

Hallak, J.C., (2006). Product Quality and the Direction of Trade, Journal of International Economics, 68(1), 238-265.

Hallak, J. C. and and Sivadasan, J., (2008). Productivity, quality and Exporting Behavior Under Minimum Quality Requirements, mimeo.

Hopenhayn, H. A., (1992). Entry and Exit and Firm Dynamics in Long Run Equilibrium, Econometrica 60(5), 1127-1150.

Hummels, D. and Klenow, P.J., (2005). The Variety and Quality of a Nation's Exports, American Economic Review, 95(3), 704-723.

Hummels, D. and Skiba, A., (2004). Shipping the Good Apples Out? An Empirical Confirmation of the Alchian-Allen Conjecture, Journal of Political Economy, 112(6), 13841402 .

Jerzmanovwski, M., (2007). Total factor productivity differences:Appropriate technology vs. efficiency, European Economic Review, 51, 20802110.

Krugman, P., (1979). A Model of Innovation, TechnologyTransfer, and the World Distribution of Income, Journal of Political Economy, 87(2), 253-266.

Linder, S., (1961). An Essay on Trade and Transformation, Stockholm: Almqvist Wiksell.

Meliz, M., (2003). The Impact of Trade on Intra-Industry Reallocations and Aggregate Industry Productivity, Econometrica 71(6), 1695-1725.

Romer, P. (1990). Endogenous Technological Change, Journal of Political Economy 98, 71-102.

Schott, P. K., (2004). Across-product Versus Within-product Specialization in International Trade, The Quarterly Journal of Economics, 119(2), 646-677.

Segerstrom, P. and Dinopoulos, E., (2006). North-South Trade and Economic Growth, Stockholm School of Economics, mimeo.

Verhoogen, E., (2008). Trade, Quality Upgrading, and Wage Inequality in the Mexican Manufacturing Sectors, The Quarterly Journal of Economics 123(2), 489-530. 


\section{Appendix}

\section{A. Conditions on fixed costs and technological lag}

The setup of the model requires that the exit cutoff in any region, $a_{x}^{J}(q)$, is lower than the export cutoff, $a_{e x}^{J K}(q)$, in order to rule out the possibility of firms not operating domestically, and producing only for the export market. To insure this we impose conditions on the fixed costs of production and export, and on the level of the technological lag of the South behind the North. With fixed export cost $c_{e x}$ higher than the fixed operational $\operatorname{cost} c_{f}$, the cutoff for exporting to the other country of the same region (North-North and South-South trade) will be higher than the exit cutoff. However, to insure higher cutoff for exporting to the other region (North-South trade) than the exit cutoff, the following condition is required

$$
\frac{c_{f}}{c_{e x}}<\frac{P^{N \frac{\alpha}{1-\alpha}} L^{N} w^{N}}{P^{S \frac{\alpha}{1-\alpha}} L^{S} w^{S}}<\frac{c_{e x}}{c_{f}}
$$

As the equlibrium wage and price indices are functions of the technological lag $\theta$, it follows that the three parameters together determine whether the condition above holds. The relative size of the population in the two regions affects the relative size of the aggregates and therefore the ratio of exit cutoffs in the North and the South, and the ordering of export cutoffs conditional on the destination country. In general, if the South is sufficiently larger than the North, the aggregates of the South might be larger than those of the North even with the relative wage smaller than one. However, the calibration exercise shows that such a large South would neither match the data on the actual size of trading partners in the North and the South nor the model could be considered as the model of North-South trade as the share of the Southern firms exporting to the North would be approaching zero. Therefore, without the loss of generality, we assume equal sizes of the regions. We find that under the wide range of $c_{f}, c_{e x}$ and $\theta$ that satisfy the stated condition, the resulting ordering of the cutoffs is such that the exit cutoff is higher in the North than in the South. Moreover, the exporters of relatively lower productivity export only to the North, while the highest productivity firms export also to the South. 


\section{B. Calibration}

Table 2: Targets and Parameters

\begin{tabular}{l|ll}
\hline \hline Targets & Data & Model \\
\hline North-North Export Share & $52.69 \%$ & $54.95 \%$ \\
North-South Export Share & $40.86 \%$ & $42.49 \%$ \\
North Exit Rate & $10 \%$ & $10.43 \%$ \\
South Exit Rate & $20 \%$ & $23.43 \%$ \\
Wage Ratio $w^{s} / w^{N}$ & 0.4 & 0.41 \\
\hline \hline Calibrated Parameters & & \\
\hline$\theta$ & 0.18 & \\
$\sigma$ & 0.5 & \\
$c_{f}$ & $11.42 \%$ & of avg North domestic employment \\
$c_{e x}$ & $29.51 \%$ & of avg North domestic employment \\
$c_{e}$ & $38 \%$ & of avg North domestic employment \\
\hline Other Parameters & & \\
\hline$\alpha$ & 0.73 & \\
$\chi$ & 0.5 & \\
$\eta$ & 0.86 & \\
$\delta$ & $0.5 \%$ & \\
$\tau$ & 1 & \\
$\bar{g}^{N}$ & 4.1 & \\
\hline \hline
\end{tabular}




\section{Size distribution and average productivities}

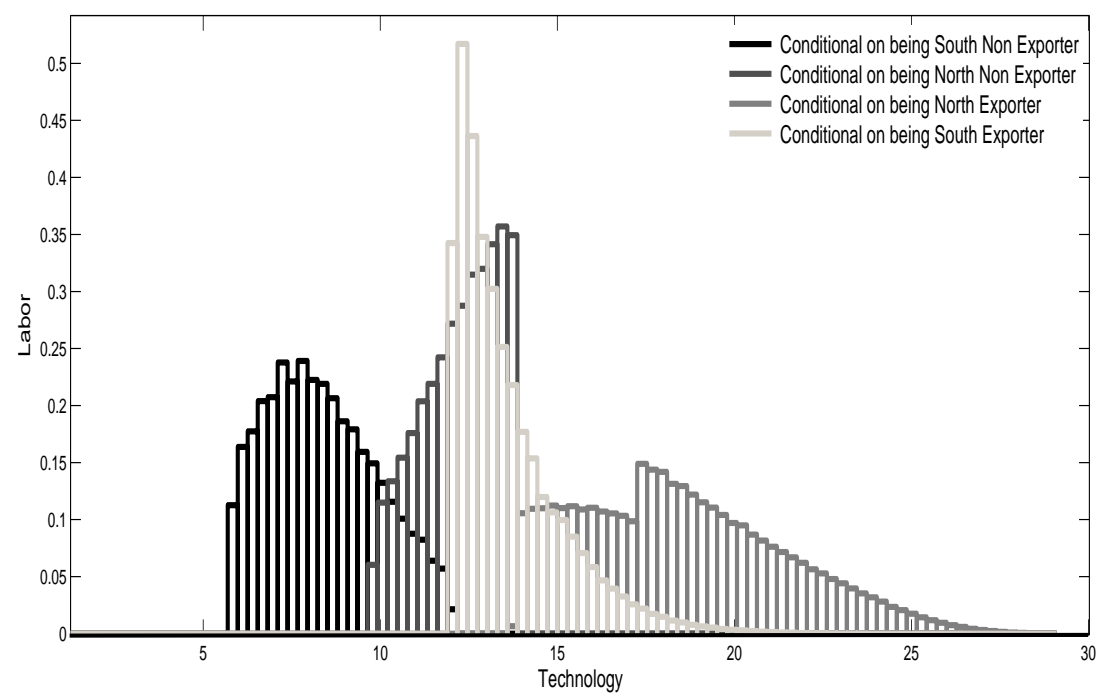

Figure 6: Conditional Labor Distribution over Technology

\begin{tabular}{l|c|c}
\hline \hline Weighted Average Technology & North & South \\
\hline Total & 16.76 & 8.38 \\
\hline Domestic & 15.01 & 8.05 \\
Export to North & 17.23 & 13.29 \\
Export to N and S & 19.79 & 16.18 \\
\hline \hline
\end{tabular}

Table 3: Weigted Average Technology Across Firm Partition 
WORKING PAPERS*

Editor: Nils Gottfries

2008:15 Henrique S. Basso, Delegation, Time Inconsistency and Sustainable Equilibrium. 24pp.

2008:16 Sören Blomquist and Håkan Selin, Hourly Wage Rate and Taxable Labor Income Responsiveness to Changes in Marginal Tax Rates. 31 pp.

2008:17 Jie Chen and Aiyong Zhu, The relationship between housing investment and economic growth in China : A panel analysis using quarterly provincial data. 26pp.

2009:1 Per Engström, Patrik Hesselius and Bertil Holmlund, Vacancy Referrals, Job Search, and the Duration of Unemployment: A Randomized Experiment. $25 \mathrm{pp}$.

2009:2 Chuan-Zhong Li and Gunnar Isacsson, Valuing urban accessibility and air quality in Sweden: A regional welfare analysis. 24pp.

2009:3 Luca Micheletto, Optimal nonlinear redistributive taxation and public good provision in an economy with Veblen effects. $26 \mathrm{pp}$.

2009:4 Håkan Selin, The Rise in Female Employment and the Role of Tax Incentives. An Empirical Analysis of the Swedish Individual Tax Reform of 1971. 38 pp.

2009:5 Lars M. Johansson and Jan Pettersson, Tied Aid, Trade-Facilitating Aid or Trade-Diverting Aid? 47pp.

2009:6 Håkan Selin, Marginal tax rates and tax-favoured pension savings of the selfemployed Evidence from Sweden. 32pp.

2009:7 Tobias Lindhe and Jan Södersten, Dividend taxation, share repurchases and the equity trap. $27 \mathrm{pp}$.

2009:8 Che-Yuan Liang, Nonparametric Structural Estimation of Labor Supply in the Presence of Censoring. 48pp.

2009:9 Bertil Holmlund, Incentives in Business and Academia. 12pp.

2009:10 Jakob Winstrand, The Effects of a Refinery on Property Values - The Case of Sweden. 27pp.

2009:11 Ranjula Bali Swain and Adel Varghese, The Impact of Skill Development and Human Capital Training on Self Help Groups. 28pp.

\footnotetext{
* A list of papers in this series from earlier years will be sent on request by the department.
} 
2009:12 Mikael Elinder. Correcting Mistakes: Cognitive Dissonance and Political Attitudes in Sweden and the United States. 25 pp.

2009:13 Sören Blomquist, Vidar Christiansen and Luca Micheletto: Public Provision of Private Goods and Nondistortionary Marginal Tax Rates: Some further Results. 41pp.

2009:14 Mattias Nordin, The effect of information on voting behavior. 34pp.

2009:15 Anders Klevmarken, Olle Grünewald and Henrik Allansson, A new consumer price index that incorporates housing. 27 pp.

2009:16 Heléne L. Nilsson, How Local are Local Governments? Heterogeneous Effects of Intergovernmental Grants. 41pp.

2009:17 Olof Åslund, Per-Anders Edin, Peter Fredriksson and Hans Grönqvist, Peers, neighborhoods and immigrant student achievement - evidence from a placement policy. $27 \mathrm{pp}$.

2009:18 Yunus Aksoy, Henrique S. Basso and Javier Coto-Martinez, Lending Relationships and Monetary Policy. 42 pp.

2009:19 Johan Söderberg, Non-uniform staggered prices and output persistence. $38 \mathrm{pp}$.

2010:1 Jonathan Gemus, College Achievement and Earnings. 43 pp.

2010:2 Susanne Ek and Bertil Holmlund, Family Job Search, Wage Bargaining, and Optimal Unemployment Insurance. 30 pp.

2010:3 Sören Blomquist and Laurent Simula, Marginal Deadweight Loss when the Income Tax is Nonlinear. $21 \mathrm{pp}$.

2010:4 Niklas Bengtsson, The marginal propensity to earn, consume and save out of unearned income in South Africa. 34 pp.

2010:5 Marcus Eliason and Henry Ohlsson, Timing of death and the repeal of the Swedish inheritance tax. 29 pp.

2010:6 Teodora Borota, Innovation and Imitation in a Model of North-South Trade. $44 \mathrm{pp}$.

2010:7 Cristiana Benedetti Fasil and Teodora Borota, World Trade Patterns and Prices: The Role of Productivity and Quality Heterogeneity. 24 pp.

See also working papers published by the Office of Labour Market Policy Evaluation http://www.ifau.se/

ISSN 1653-6975 